REVISTA DE DERECHO UNED, NÚM. 18, 2016

\title{
ACERCA DE LA REVOCATORIA DE MANDATO Y SU HIPOTÉTICA APLICACIÓN EN ESPAÑA
}

\author{
ON THE RECALL ELECTION AND ITS HIPOTETICAL \\ APPLICATION AT SPAIN
}

\begin{abstract}
ALFREDo RAMÍrez NÁRDIZ
Profesor Contratado Doctor (acreditado ANECA), Facultad de Derecho, Universidad Libre, Seccional Barranquilla km 7. Antigua vía a Puerto Colombia. A. A. 1752, Barranquilla, Colombia aramirez@unilibrebaq.edu.co

0034665435929
\end{abstract}

Resumen: La revocatoria de mandato es una instrumento jurídico propio de la democracia participativa, bien conocida en diversos países de América, pero inexistente en España, que permite a los ciudadanos pronunciarse mediante una votación sobre la continuidad o terminación del mandato de un gobernante elegido previamente por ellos. La revocatoria se constituye así en un mecanismo de control que la ciudadanía ejerce sobre sus gobernantes en modelos presidencialistas que no prevén la moción de censura parlamentaria sobre dichos gobernantes al haber sido elegidos estos no por una asamblea representativa, sino por los ciudadanos. Partiendo del conocimiento del concepto de la revocatoria de mandato, así como del ejemplo de la regulación y práctica de la revocatoria de mandato en dos países, Colombia y Venezuela, resulta de interés plantearse las posibilidades de regular y aplicar esta institución en España. Esto es, si sería posible aplicarla, cómo sería posible hacerlo, qué modificaciones sería necesario practicar, en su caso, en el ordenamiento español y, particularmente, si supondría una mejora en el modelo democrático español o si, por el contrario, no supondría mejora alguna, o incluso, si supondría un empeoramiento del modelo de control espa-

() UNED. Revista de Derecho UNED, núm. 18, 2016 


\section{ALFREDo RAMÍREZ NÁRDIZ}

ñol sobre los gobernantes. El modelo de control español, de tipo parlamentario, concibe la moción de censura como instrumento esencial para que la asamblea representativa controle al gobernante elegido previamente por ella. ¿En qué modo sería posible introducir en un modelo de este tipo un instrumento como la revocatoria de mandato? Posiblemente, el modo más sencillo sería modificando el modelo y haciéndolo presidencialista para que sean los ciudadanos los que elijan al gobernante y, por ello, puedan eventualmente deponerlo mediante la revocatoria. ¿Supondría eso una mejora en el modelo o simplemente un cambio de modelo desde el parlamentario al presidencialista? En los actuales momentos, en los que no son pocas las voces que plantean y solicitan cambios en el sistema político español, resulta de especial interés reflexionar sobre un instrumento jurídico como la revocatoria de mandato y su posible introducción en España, exponiendo sus potenciales ventajas de mejora y profundización democrática, pero también sus posibles problemas de populismo y simplificación del discurso político.

Abstract: The recall is a legal tool that belongs to participatory democracy, well known at many countries of Amercia, but non-existent at Spain, that allows citizens to decide through a votation on the continuity or ending of the mandate of a governor previously elected by them. Recall is in this way a control mechanism that citizenship has over their rulers on presidential models that don't foresee the parliamentary censure over those rulers because of have been elected not by a representative assembly but by citizens. Starting from the knowledge of the recall concept, as well as of the example of the regulation and practice of recall in two countries, Colombia and Venezuela, it is interesting to think on the chances to regulate and apply this institution on Spain. This is, if it would be posible to apply it, how would be posible to do it, what modifications would be necessary to practice in the spanish regulation or, conversely, it would not mean any improvement, or even, if it would suppose a worsening of the spanish control model over rulers. The spanish control model, parliamentary kind, has the parliamentary censure as essential tool to allow the representative assembly to control the previously chosen ruler. How would be possible to introduce in a model like this a tool as recall? Possibly, the easiest way would be by modifying the model and changing it into a presidential one to allow citizens to choose the president and, therefore, they can eventually to depose him through the recall. Would suppose that an improvement of the model or simply a change of model from the parlamentary one to the presidential one? Nowadays, when not only a few voices suggest and ask changes 
in the spanish political system, it is of special interest to meditate on a legal tool as recall as its possible introduction in Spain, showing its potential advantages of improvement and democratic deepening, but also its possible problems of populism and simplification of the political discourse.

Palabras clave: Revocatoria, España, aplicación, elección directa, gobernantes.

Keywords: Recall, Spain, application, direct election, rulers.

Recepción original: 17/02/2016

Aceptación original: 6/04/2016

Sumario: I. Introducción. II. La revocatoria de mandato. 1. Concepto. 2. El caso colombiano: la primera experiencia suramericana. 3. El caso venezolano: la revocatoria del Presidente de la República. III. La revocatoria en España. 1. Una cuestión de modelo: presidencialismo y parlamentarismo. 2. Introducción de la revocatoria en el Derecho español: elección directa y revocatoria. 3. Posibles consecuencias de la revocatoria. IV. Conclusiones.

Summary: I. Introduction. II. The recall. 1. Concept. 2. The Colombia case: the first Southamerican experience. 3. The Venezuela case: recall of the President of the Republic. III. Recall at Spain. 1. A matter of model: presidentialism and parliamentarism. 2. Introduction of recall in Spanish Law: direct election and recall. 3. Possible consequences of recall. IV. Conclusions.

\section{INTRODUCCIÓN ${ }^{1}$}

En democracia el control sobre el gobernante es esencial. Todo ejercicio de poder político debe poder ser controlado y aquellos que han sido elegidos por la ciudadanía para representarlos y gobernarlos deben poder ser controlados por dicha ciudadanía. El instrumento de control más inmediato es el ejercicio del voto, el cual puede mantenerse o retirarse del cargo público electo en función de que se desee que continúe o no en el ejercicio de sus funciones. Si el voto se constituye como el instrumento de control propio de los ciudadanos sobre sus gobernantes, en los sistemas parlamentarios los

${ }^{1}$ Este artículo es producto del proyecto de investigación «Transformaciones democráticas y democracia participativa» perteneciente al grupo de investigación «Poder público y ciudadanía» de la Universidad Libre, Seccional Barranquilla, km. 7. Antigua vía a Puerto Colombia. A. A. 1752, Barranquilla, Colombia. aramirez@unilibrebaq.edu.co 


\section{ALFREdo RAMÍREZ NÁRDIZ}

controles parlamentarios, dentro de los cuales destaca poderosamente la moción de censura, son el instrumento de control de la asamblea representativa sobre el primer ministro o presidente del gobierno elegido por ella.

Correlato de la idea de control, es la idea de responsabilidad. Si el que es representado en el ejercicio del poder público ejerce control sobre aquel a quien ha elegido, aquel que ejerce el poder es responsable frente a quien le ha elegido. Los representantes son responsables para con sus electores (para el conjunto de todos ellos, pues la prohibición del mandato imperativo impide predicar responsabilidad directa frente a los electores concretos del representante) y, en un sistema parlamentario, el gobernante, aquel que ejerce el poder ejecutivo, es responsable para con la asamblea representativa que le ha elegido. Pero, en un modelo presidencialista, ¿quién ejerce control sobre un gobernante y para con quién es responsable dicho gobernante, si es elegido directamente por los ciudadanos? Más allá de los distintos controles entre las diferentes instituciones del Estado que fije cada ordenamiento, en principio, pueden ser los propios ciudadanos quienes ejerzan el control y para con quienes sea responsable el gobernante. Ese control lo pueden llevar a cabo a través de su voto. Pero también, y como sucede en distintos Estados, a través de la revocatoria de mandato.

La revocatoria ${ }^{2}$ de mandato implica una relación directa entre el ciudadano y el gobernante elegido por el ciudadano. En ella no actúa un órgano intermedio formado por representantes elegidos por el ciudadano que retira al gobernante la confianza previamente otorgada, como sucede en un sistema parlamentario. La revocatoria aparece en el marco de un sistema presidencialista como contrapartida a la elección directa del gobernante por los ciudadanos. Si el ciudadano elige directamente al gobernante, él es el llamado a ejercer un control sobre el gobernante y, en su caso, cesarle. La revocatoria materializa dicho control.

${ }^{2}$ Es posible encuadrar la revocatoria dentro de lo que en el presente se denomina mayoritariamente como democracia participativa, la cual podría entenderse como el conjunto de instrumentos participativos cuya introducción se pretende en la democracia representativa para mejorarla y profundizar en ella mediante una mayor participación de los ciudadanos en la toma de las decisiones políticas, así como para lograr un mejor control de estos sobre sus gobernantes. Para ampliar información sobre la democracia participativa, vide RAMÍREZ NÁRDIZ, A. Democracia participativa. La democracia participativa como profundización en la democracia, Tirant lo Blanch, Valencia, 2010 o RAMÍREZ NÁRDIZ, A. Guía práctica de la democracia participativa. Conocer la democracia participativa y aprender a usarla, Dykinson, Madrid, 2012. 
Siendo, en principio, la revocatoria de mandato una herramienta de control aplicable a un modelo presidencialista de elección de gobernantes, la cuestión radica en si la misma puede aplicarse a un modelo parlamentario como, por ejemplo, lo es el español. La pregunta que cabría hacerse sería, ¿qué autoridad tienen los ciudadanos para, en un sistema parlamentario, revocar el mandato de un gobernante al que ellos realmente no han elegido? Si aquel que elige y otorga su confianza es el que puede revocarla, es la asamblea representativa que ha elegido al ejecutivo quien puede deponerle, no la ciudadanía. A quien puede deponer la ciudadanía es a los miembros de dicha asamblea, a los que sí ha elegido, a través de la retirada de su confianza manifestada en el voto en elecciones periódicas, pero no a los cargos políticos elegidos por ella. Desde esta perspectiva, la revocatoria de mandato no sería propia del modelo parlamentario y, por ello, no se podría introducir en el ordenamiento español. Si se quisiera hacer, posiblemente habría que cambiar este ordenamiento en la dirección de convertirlo en presidencialista, esto es, que alcaldes, presidentes autonómicos o el Presidente del Gobierno fueran elegidos directamente por los ciudadanos.

Si se planteara hacer esto así, la cuestión sería si con semejante reforma se ganaría en calidad democrática o si sucedería lo contrario. Desde la defensa de la democracia participativa se puede argumentar que cualquier aumento de la participación directa de los ciudadanos en el gobierno (y la revocatoria es claramente uno, así como podría interpretarse que la elección directa de gobernantes podría ser otro) supone en sí una mejora democrática. En sentido contrario, se puede indicar que la revocatoria simplifica y polariza la decisión sobre la revocación del gobernante, mientras que los sistemas parlamentarios de control permiten tanto un control más continuado, como más razonado y argumentado y que, en cualquier caso, establecer una relación directa entre ciudadanos y gobernantes reduciendo el rol del parlamento puede desembocar en un debilitamiento de las instituciones, o incluso en fenómenos caudillistas y populistas.

Desde las presentes líneas se pretende contribuir a la reflexión sobre la revocatoria de mandato y su posible inclusión en un sistema político tan aparentemente lejano a la misma como es el español. Así, en primer lugar, se expondrá el concepto de la revocatoria de mandato, junto con su ejercicio en dos países que pueden ser tenidos como ejemplos relevantes (bien por ser de los primeros en regularla constitucionalmente, bien por el alcance al que ha llegado su práctica en ellos), Colombia y Venezuela, que la han practicado y que la continúan practicando, para, a continuación 
proceder a estudiar las posibilidades de la introducción de la revocatoria en España, las reformas que, en su caso, habría que hacer para introducirla y las posibles consecuencias que podría tener dicha introducción.

\section{LA REVOCATORIA DE MANDATO}

\section{Concepto}

La revocatoria de mandato podría definirse como la «facultad de la ciudadanía de retirar del ejercicio de sus funciones a un cargo político o a un funcionario público antes del vencimiento de su plazo de ejercicio». ${ }^{3}$ La finalidad de la revocatoria es permitir que aquellos ciudadanos no satisfechos con el desempeño del gobernante puedan retirarle su confianza y deponerle ${ }^{4}$. Es, por tanto, un instrumento participativo cuya finalidad es constituirse en herramienta de $\operatorname{control}^{5} \mathrm{y}$ de exigencia de responsabilidad sobre los gobernantes ${ }^{6}$.

Aunque cabría la posibilidad de concebir como tal la revocatoria propuesta por el propio Poder Ejecutivo que se somete a ella voluntariamente (revocatoria «desde arriba») ${ }^{7}$, la práctica parece demostrar que la revocatoria se inicia esencialmente a propuesta de los ciudada-

${ }^{3} \mathrm{Al}$ respecto vide «Glosario». Ibídem, 2012.

${ }^{4}$ Los motivos aducidos por los ciudadanos para iniciar una revocatoria son diversos. Por citar, por ejemplo, algunos alegados en 2012 en Perú (donde es necesario dar -aunque no probar- un motivo para iniciar el proceso): incumplimiento de promesas electorales, incapacidad de gestión, malversación de fondos, incumplimiento de funciones, falta de transparencia y rendición de cuentas, nepotismo, abuso de autoridad, sobrevaloración de obras, corrupción, autoritarismo, o, incluso, incapacidad moral. TUESTA SOLDEVILLA, F. «Perú: entre la participación y la gobernabilidad local: 1997-2013» en WELP, Y. Y SERDÜLT, U. (COORDS.) La dosis hace el veneno. Análisis de la revocatoria de mandato en América Latina, Estados Unidos y Suiza, Instituto de la Democracia, Quito, 2014, pp. 13-14.

${ }^{5}$ Pues, como indica SUBIRATS citando a BECK: «El ciudadano que quiere resolver los problemas que no han sabido ni prever ni evitar los especialistas, se los encuentra de nuevo entre sus manos. No tiene otra solución que mantener la delegación (a los políticos y especialistas), pero multiplicando esta vez los dispositivos para controlarlos y vigilarlos». SUBIRATS I HUMET, J. «¿Qué democracia tenemos? ¿Qué democracia queremos?», Historia actual online, n 26, otoño 2011, pp. 115-116.

${ }^{6}$ Respecto de los cuales, y merced a la revocatoria, se rompe una de las ficciones que, para SUBIRATS citando a ROSANVALLON, sustentan la democracia: «el triunfo mayoritario el día concreto de las elecciones y, por consiguiente, la legitimidad conseguida ese día, se traslada automáticamente a todo el tiempo en que va durar el mandato». Ibídem, p. 116.

${ }^{7}$ Caso de la revocatoria boliviana sobre Evo Morales de 2008. 
nos (revocatoria «desde abajo») mediante la recogida de un número de firmas equivalente a un tanto por ciento determinado legalmente de los votantes que participaron en su día en la elección del cargo al que se busca ahora revocar ${ }^{8}$. La revocatoria aparece, en definitiva, como un mecanismo de control que se constituye en la contrapartida a la elección directa de un cargo público por los ciudadanos: los mismos que le nombran pueden cesarle ${ }^{9}$.

La evidente controversia que puede generar este mecanismo radica en la cuestión de si el mismo no se constituye en una especie de mandato imperativo por el cual el gobernante sabe que o bien cumple con sus promesas a sus votantes (o, al menos, que estos interpreten que lo ha hecho), o bien se expone a ser depuesto del cargo. No en vano, la revocatoria de mandato puede ir acompañada del voto programático, esto es, de la obligación legal del gobernante de cumplir su programa electoral bajo el riesgo cierto de que, de no cumplirlo, se le podrá someter a una revocatoria y expulsarlo del cargo. ¿Implica esto una forma de mandato imperativo?

Podría concluirse que sí, si se concibe la prohibición del mandato imperativo como aplicable a cualquier cargo político elegido por los ciudadanos, ya sea del legislativo o del ejecutivo. Si se considera, por el contrario, que la prohibición del mandato imperativo es, en esencia, predicable del poder legislativo y de los represen-

${ }^{8}$ En este sentido, distinguiendo entre dos categorías de revocatoria indica GÓMEZ CAMPOS: «existen al menos dos tipos generales de revocatorias de mandato: la revocatoria completa; y la revocatoria mixta. Esta última refiere al proceso en el cual la ciudadanía participa sólo en una de las fases, ya sea convocándolo o bien, decidiendo mediante referéndum. En la revocatoria mixta, usualmente una autoridad política legalmente reconocida tiene la facultad de someter a consideración del electorado la remoción del funcionario público en cuestión, y es el electorado el que finalmente decide si procede la remoción o no. Por otro lado, la revocatoria completa consiste en el procedimiento por el cual ambas etapas, la iniciativa y la decisión final, recaen exclusivamente en la ciudadanía». GÓMEZ CAMPOS, S. «Mecanismos de democracia directa en América Latina: una revisión comparada», Revista de Derecho electoral, $n^{\circ} 10$, segundo semestre, San José, Costa Rica, 2010, p. 27.

${ }^{9}$ Otra posible definición podría indicar que la revocatoria de mandato es «un mecanismo de democracia directa (MDD) susceptible de ser activado por la ciudadanía, para consultar en un referéndum vinculante sobre la interrupción del mandato de una autoridad electa (...) la revocatoria ha sido introducida para contrarrestar o evitar problemas -la corrupción, la distancia entre gobernantes y gobernados, el escaso apego de los primeros a cumplir con sus promesas de campaña, el déficit de espacios de intervención directa de la ciudadanía en la definición de los asuntos públicos-, pero no necesariamente o no siempre ha producido el resultado deseado». WELP, Y. Y SERDÜLT, U. (COORDS.) op. cit., 2014, p. 2. 


\section{ALFREDo RAMÍREZ NÁRDIZ}

tantes que lo forman ${ }^{10}$ (los cuales, aun y elegidos por unos ciudadanos concretos, representan a toda la Nación y por ello no deben someterse a la voluntad de sus electores específicos) y que no afecta a los titulares de ningún ejecutivo, aun y pensando que la revocatoria de mandato implicase en algún modo mandato imperativo o una consecuencia del mismo, no se debería considerar la revocatoria como contraria al espíritu de la prohibición del mandato imperativo, pues no es sobre legisladores que se deban a toda la Nación, sino sobre gobernantes que se deben a la comunidad concreta que los ha elegido para gobernarlos (en modelos de elección directa) sobre quien se aplica.

En cualquier caso, es innegable que la existencia de un voto programático (como obligación legal, y no sólo moral, de ceñirse al programa electoral) y una consecuente revocatoria de mandato, han de ejercer necesariamente una no pequeña influencia en el gobernante y en sus decisiones, comprometiendo potencialmente su libertad de acción y estableciendo una relevante amenaza sobre su acción de gobierno. Visto así, si existe revocatoria el gobernante no es libre, sino que está sujeto a que sus electores decidan que no ha cumplido con su programa y procedan a votar su expulsión del cargo. Si la libertad de gobernar puede ser puesta en entredicho por aquellos que eligieron al gobernante, si podría como mínimo considerarse que cabe que se genere una situación similar a la propia del mandato imperativo. La cuestión es si al existir dicho mandato sobre un gobernante directamente elegido por los ciudadanos y no sobre un miembro de una asamblea legislativa, se considera como tal o no. Si se opta por considerar que la prohibición del mandato imperativo surge para garantizar que los miembros de los primeros parlamentos liberales no fueran meros delegados, sino representantes que libremente y desde su razón conformaran la voluntad de la Nación, la revocatoria de mandato, al predicarse de otros sujetos bien distintos, nada tendría que ver con el mandato imperativo. Si se opta por considerar que cualquier limitación a la libertad de actuación política del gobernante por parte de sus electores es un mandato imperativo, entonces sí que la revocatoria podría ser vista como una modalidad de mandato imperativo.

${ }^{10}$ En este sentido parece posicionarse el art. 67.2 CE cuando indica que «los miembros de las Cortes Generales no estarán ligados por mandato imperativo». Es decir, hace referencia a la prohibición del mandato imperativo como un rasgo característico y propio de los miembros del legislativo. 
Independientemente de esto, lo cierto es que la revocatoria de mandato goza de mucha más popularidad en el continente americano que en Europa ${ }^{11}$, fruto posiblemente de la preponderancia de los modelos presidencialistas en dicho continente frente a los parlamentarios mayoritarios en Europa. En EEUU ${ }^{12}$ más de veinte Estados la regulan (el caso tal vez más famoso sea el de la revocatoria del gobernador de California Gray Davis que permitió que en 2003 el actor Arnold Schwarzenegger fuera elegido gobernador ${ }^{13}$ ) y en Hispanoamérica diversos países como Perú ${ }^{14}$-art. 31 Constitución del Perú de

${ }^{11}$ Esto no significa que la revocatoria sea completamente ajena a Europa. Así, ya en la Constitución de Weimar de 1919 se indicaba en su art. 43: "El cargo de Presidente del Imperio dura siete años, siendo posible la reelección. Antes de que expire este plazo, el Presidente del Imperio, a propuesta del Reichstag, puede ser depuesto mediante el voto popular. El acuerdo del Reichstag requiere mayoría de dos tercios, y una vez adoptado, cesará el Presidente en el ejercicio de su función. Si la propuesta de destitución es rechazada por el voto popular, se entenderá que ello equivale a una reelección del Presidente, y el Reichstag quedará disuelto como consecuencia».

${ }^{12}$ No en vano, es posible situar el origen de la práctica de la revocatoria de mandato -recall en su nomenclatura estadounidense- en los EEUU a finales del siglo XIX. MARTÍNEZ CÁRDENAS, E. E. «Revocatoria de mandato: ¿ataque a la democracia representativa?», Reflexión política, UNAB, Colombia, año 15, $\mathrm{n}^{\circ} 29$, junio de 2013, p. 87. Aunque hay autores que buscan su origen mucho antes: «El primer caso de introducción de la revocatoria se remonta a las leyes del Tribunal General de la Colonia de la Bahía de Massachusetts en 1631 y a la Carta de Massachusetts de 1691. Una de las disposiciones de la Constitución de Pennsylvania de 1776 concedía al pueblo el derecho, en los períodos que considerara convenientes, de reducir la posición de sus servidores públicos a la situación privada». QVORTRUP, M. «La experiencia estadounidense de 1776 a 2012», en WELP, Y. Y SERDÜLT, U. (COORDS.) op. cit., 2014, pp. 209-210, citando a SANTOS, H. J. Birth of a Liberal State: Connecticut's Fundamental Orders, The Connecticut, Law Review, 1, 1968 y a ZIMMERMAN, J. F. The Recall: Tribunal of the People, Westport, Connecticut, Praeger, 1997.

13 «Fue cuando Arnold Schwarzenegger, un actor cuyas películas incluyen justamente una titulada Total Recall -nota: juego de palabras, pues recall puede traducirse como recordar, ese es el significado dado en el título de la película, o como revocatoria- declaró que desafiaría al gobernador demócrata Gray Davis. En su aparición en el conocido show de David Letterman, el austriaco físicoculturista que se convirtió en actor y luego en político, parafraseo su famosa frase en la película Terminator: «Hasta la vista Gray Davis». Schwarzenegger ganó en buena ley las elecciones revocatorias del 2003 y Davis se convirtió en el primer gobernador revocado desde la remoción de Lynn Frazier (gobernador de Dakota del Norte) en 1921 ». WELP, Y. Y SERDÜLT, U. (COORDS.) op. cit., 2014, pp. 207-208.

${ }^{14}$ Perú sea posiblemente el país que más revocatorias de mandato ha realizado. Se calcula que más de 5.000 autoridades han sido sometidas a una revocatoria. Ibídem, pp. 2-3. Para algunos autores la practica peruana no sería especialmente edificante, pues más que servir como control de los ciudadanos sobre sus gobernantes, su uso ha ido dirigido esencialmente a ser herramienta de la minoría derrotada en las elecciones para boicotear la acción de gobierno del gobernante elegido por la mayoría. MARTÍNEZ CÁRDENAS, E.E. op. cit., 2013, p. 87, citando a TUESTA, F. Reforma política en Perú, Biblioteca Jurídica Virtual del Instituto de Investigaciones Jurídicas, UNAM, 2009. 
1993-, Ecuador ${ }^{15}$-art. 105 Constitución de Ecuador de 2008-, Bolivia $^{16}$-art. 11. II.1 Constitución de Bolivia de 2009-, Colombia o Venezuela $^{17}$ la regulan y practican ${ }^{18}$.

\section{El caso colombiano: la primera experiencia suramericana}

Colombia fue el primer país suramericano en recoger en su Constitución en 1991 la revocatoria de mandato ${ }^{19}$. La Constitución recoge la revocatoria de mandato en los arts. 40 y 103 indicando que es uno de los mecanismos de participación de la ciudadanía en el ejercicio de la soberanía y que, para hacer efectivo el derecho de los ciudadanos a participar en la conformación, ejercicio y control del poder político, una de las facultades que dichos ciudadanos tienen es revocar el mandato de los elegidos. Se regula en los artículos 6 y 64 a 76 de la Ley 134, así como, en lo relativo al voto programático, en la Ley 131, ambas de $1994^{20}$.

${ }^{15}$ Revocatoria de la que se denuncia haber sido reformada posteriormente a su inclusión en la Constitución de 2008 al efecto de desactivarla como instrumento participativo susceptible de inquietar al poder político. CASTELLANOS SANTAMARÍA, A. S. «Ecuador: la transformación de las reglas del juego y sus consecuencias (1998-2013)» en WELP, Y. Y SERDÜLT, U. (COORDS.) op. cit., 2014, p. 104.

${ }^{16}$ En Bolivia se realizó una pregunta a la ciudadanía sobre la acción de gobierno del Presidente Evo Morales en agosto de 2008, antes incluso de aprobada la Constitución, siendo ratificado con el $67.4 \%$ de los votos. Esta pregunta podría tal vez calificarse como un plebiscito, más que como una revocatoria propiamente dicha, atendiendo tanto a que fue promovida desde el Ejecutivo y no desde la ciudadanía, como a que la pregunta formulada no inquiría sobre la continuidad en el cargo del gobernante, sino sobre el apoyo a la dirección de sus políticas: «¿Usted está de acuerdo con el proceso de cambio liderizado por el Presidente Evo Morales Ayma y el Vicepresidente Álvaro García Linera?». BOLIVIA. VICEPRESIDENCIA DE LA REPÚBLICA. UNIDAD DE INFORMACIÓN PARA LA PARTICIPACIÓN CIUDADANA. Resultados electorales. Referéndum revocatorio 2008, 2008, www.vicepresidencia.gob.bo/spip. php?page $=$ publicaciones\&id_mot=9 Consultado, 14 octubre 2014 .

${ }^{17}$ LISSIDINI, A. «¿Cómo investigar la Democracia Directa? Explicaciones, interpretaciones y prejuicios.» Documento de Trabajo, n. ${ }^{\circ} 27$, Escuela de Política y Gobierno, Universidad Nacional de San Martín, Argentina, noviembre 2007, p. 4.

${ }^{18}$ No es esta una lista cerrada de países. Por poner sólo otro ejemplo, quepa citar la revocatoria de mandato existente en Costa Rica. Vide RIVERA SÁNCHEZ, J. L. «Revocatoria del mandato para funcionarios de elección popular en los gobiernos locales", Revista de Derecho electoral, $\mathrm{n}^{\circ} 2$, segundo semestre, San José, Costa Rica, 2006, pp. 1-44.

${ }^{19}$ Ya en 1923 para Córdoba y en 1933 para Entre Ríos, Argentina reguló la revocatoria de mandato, si bien siempre en el ámbito regional, no en el nacional y no regulada por la Constitución nacional. WELP, Y. Y SERDÜLT, U. (COORDS.) op. cit., 2014, pp. 4-5.

${ }^{20}$ República de Colombia. Ley 131 de 1994 (mayo 9), por la cual se reglamenta el voto programático y se dictan otras disposiciones; Ley 134 de 1994 (mayo 31), por la cual se dictan normas sobre mecanismos de participación ciudadana. Modi- 
La revocatoria es un derecho político por el cual los ciudadanos dan por terminado el mandato que han conferido al gobernador o al alcalde -que no al Presidente de la República, a quien no se aplica-. La revocación del mandato mediante una nueva votación debe ser solicitada ante la Registraduría Nacional mediante un memorial que suscriban los ciudadanos en número no inferior al $40 \%$ del total de votos que obtuvo el elegido.

La revocatoria sólo puede iniciarse cuando haya transcurrido un año como mínimo desde la toma de posesión del gobernador o el alcalde. Siempre se deberán exponer los argumentos por los cuales se pide; expedida la certificación que apruebe la solicitud de realizarla, la votación se hará en dos meses; el mandato del gobernador o del alcalde será revocado si la votación es aprobada por la mitad más uno de los votos, siempre que el número de sufragios no sea inferior al 55 $\%$ de la votación válida registrada el día en que se eligió al respectivo mandatario ${ }^{21}$.

Si la revocatoria no fuera exitosa, no podrá volver a convocarse otra en el mismo mandato del gobernador o alcalde; en el caso de que sí fuera exitosa, la remoción del mandatario será inmediata y en los treinta siguientes se celebrarán elecciones para la elección del sustituto. Durante estos días se nombrará un interino del mismo partido del ex-mandatario. Puede inscribirse como candidato a sustituto (un mínimo de veinte días ante de la votación) cualquier ciudadano que cumpla los requisitos para ello, a excepción del exmandatario.

La revocatoria de mandato ha de entenderse íntimamente relacionada con la institución del voto programático, regulada en la Ley 131

ficadas por la Ley 741 de 2002 (mayo 31), por la cual se reforman las Leyes 131 y 134 de 1994, Reglamentarias del voto programático. Ambas leyes deben ser interpretadas desde las sentencias de la Corte Constitucional C-011 de 1994 (para la Ley 131) y C-180 de 1994 (para la Ley 134).

${ }^{21}$ Los tantos por ciento exigidos para poder convocar y aprobar una revocatoria, aun y siendo en el presente más accesibles que lo que eran originalmente (hasta la reforma introducida por el art. 2 de la Ley 741 de 2002, los artículos 11 de la Ley 131 y 69 de la Ley 134 indicaban que la revocatoria se aprobaba por no menos del $60 \%$ de los votantes y siempre que el número de votos emitido no fuera inferior al $60 \%$ de aquellos que se emitieron el día en que se eligió al mandatario revocado, pudiendo votar sólo aquellos que en su día votaron para elegir a dicho mandatario), pueden ser considerados duros en un país con unas tasas de participación tan bajas como lo es Colombia (menos del 48\% de participación en la segunda vuelta de las elecciones presidenciales de 2014. COLOMBIA. REGISTRADURÍA NACIONAL DEL ESTADO CIVIL, http://www3.registraduria.gov.co/presidente2014/preconteo/2v/99PR2/ DPR9999999_L1.htm Consultado, 16 octubre 2014). La exigencia de estos elevados porcentajes puede ayudar a explicar el escaso número de revocatorias que salen adelante en Colombia. 


\section{AlFREdo RAmírez NÁRDIZ}

de 1994 en desarrollo del art. 259 de la Constitución, el cual es «el mecanismo de participación mediante el cual los ciudadanos que votan para elegir gobernadores y alcaldes, imponen como mandato al elegido el cumplimiento del programa de gobierno que haya presentado como parte integral en la inscripción de su candidatura». Este programa de gobierno será inscrito ante las autoridades electorales y se publicará oficialmente, siendo su incumplimiento -o la interpretación ciudadana de su incumplimiento- el motor que generara, en su caso, el comienzo del procedimiento de la revocatoria de mandato. Por poder ser visto como una especie de mandato imperativo, el voto programático resulta especialmente relevante y no poco polémico.

La revocatoria es (junto con el cabildo abierto) de los pocos instrumentos participativos colombianos cuyo ejercicio ha sido y es real superando la mera regulación teórica. Así, la Registraduría Nacional del Estado Civil ${ }^{22}$ constata que en el año 2013 se iniciaron en Colombia 36 revocatorias, frente a 2 referendos, 2 consultas y 1 iniciativa popular. No obstante, el relevante número de revocatorias iniciadas no implica un equivalente número de revocatorias que hayan prosperado, pues ese mismo año 2013 de todas las presentadas sólo dos prosperaron ${ }^{23}$. Frente a estos números, es relevante tener en cuenta que la Procuraduría General de la Nación puede destituir alcaldes y gobernadores y que entre 1999 y 2012 lo hizo con más de 850 de ellos ${ }^{24}$.

${ }^{22}$ COLOMBIA. REGISTRADURÍA NACIONAL DEL ESTADO CIVIL, Ranking de mecanismos de participación por departamentos, www.registraduria.gov.co/-Revocatoria-de-mandato,394-.html Consultado, 12 agosto 2014.

${ }^{23}$ En números absolutos los resultados desde 1991, año de aprobación de la Constitución, tampoco son especialmente alentadores. En palabras de Rivera Ardila y Cardona Saldarriaga: «En Colombia desde la vigencia de la Constitución Política de 1991 hasta el año 2011 se han promovido 71 procesos de revocatoria de Alcaldes, de las cuales 47 se adelantaron entre febrero de 2009 a junio de 20102, y de estos, en 12 fueron certificadas las firmas y convocadas las elecciones, para un total de 36 convocatorias a votación, todos de ellos fallidos el intento de revocatoria, al no lograrse el umbral requerido en las urnas para el retiro del cargo del respectivo mandatario». RIVERA ARDILA, R. Y CARDONA SALDARRIAGA, R. «La revocatoria del mandato: estudio de caso alcalde de Pradera Valle 2008-2011», Memorando de Derecho, año 2, $\mathrm{n}^{\circ} 2$, Universidad Libre, Seccional Pereira, Colombia, 2011, p. 226.

${ }^{24}$ «El dato no es menor: la Procuraduría ha destituido a 780 alcaldes y a 71 gobernadores entre 1999 y 2012. Para julio de 2011 la Procuraduría había sancionado a más de trescientos alcaldes, mientras entre enero de 2009 y abril de 2012 fueron sancionados o condenados diez gobernadores y seis ex gobernadores. Aunque muchos de los sancionados e inhabilitados lo han sido por desconocimiento o mala asesoría en el manejo de las normas o por participación indebida en política, muchos lo han sido por corrupción y malos manejos (el 40\%, según la Procuraduría)». FRANCO CUERVO, A. B. «Colombia: instituciones, líderes políticos y abstención electoral (1991-2013)» en WELP, Y. Y SERDÜLT, U. (COORDS.) op. cit., 2014, p. 61. 
De entre ellas, se podría destacar, tanto por la importancia de la ciudad, como por la relevancia política del personaje, como por el elevado número de firmas movilizadas, la presentada contra el alcalde de Bogotá, Gustavo Petro, la cual fue cancelada al destituirse (y posteriormente restituirse) al mandatario. Se presentaron 641.707 firmas solicitando la revocatoria, de las cuales fueron validadas 357.250 , lo cual superó ampliamente el umbral mínimo necesario de 289.263. Para que la revocatoria prosperara se hubieran necesitado 1.234.214 firmas favorables a la misma. Se fijó la fecha de la votación el 6 de abril de 2014 (casi un año después de entregadas las firmas el 18 de abril de 2013), pero, finalmente, el tortuoso proceso abierto en diciembre de 2013 cuando la Procuraduría General de la Nación destituyó a Petro a causa de su desempeño como alcalde tuvo, entre otras consecuencias, que la revocatoria fuera cancelada ${ }^{25}$.

No es posible dejar de destacar la compleja relación entre la teoría legal colombiana y su puesta en práctica real ${ }^{26}$. Este fenómeno se materializa también en el ámbito de la democracia participativa y, en él, en la revocatoria de mandato ${ }^{27}$. En este sentido:

«(...) se puede afirmar que en Colombia la democracia participativa es formal y no se ha logrado que la ciudadanía tome conciencia de la importancia de su participación en asuntos que afectan a la comunidad, y los que participan, muchos lo hacen por intereses personales (...) Las prácticas políticas electorales corruptas, como la compra de votos, el abuso del poder, el juego de intereses tales como las alianzas y coaliciones, han hecho del mecanismo de participación un instrumento de presión y negociación entre las distintas fuerzas políticas, y se aleja de ser en la práctica un instrumento de control político ciudadano que impide que se imponga la real voluntad popular ${ }^{28}$.»

Los requisitos exigentes para su convocatoria, la participación escasa de los ciudadanos en las convocatorias electorales, la falta de

${ }^{25}$ COLOMBIA. REGISTRADURÍA NACIONAL DEL ESTADO CIVIL, www.registraduria.gov.co/-Oficios-revocatoria-de-mandato-del-.html Consultado, 12 de agosto de 2014.

${ }^{26}$ «Ana Beatriz Franco Cuervo indica que la democracia participativa promovida en la Constitución de 1991 fue concebida como una respuesta a los numerosos problemas que asolaban a la democracia colombiana. Sin embargo, a primera vista $-\mathrm{y}$ en particular en lo que concierne a la revocatoria-, el nuevo andamiaje institucional no parece haber tenido una influencia destacable». WELP, Y. Y SERDÜLT, U. (COORDS.) op. cit., 2014, p. 3.

27 «Se observa también que la mayoría de las revocatorias no han sido promovidas por los partidos o la ciudadanía, sino por ex alcaldes o gobernadores, candidatos derrotados o precandidatos electorales, que en defensa de intereses personalistas abusan del mecanismo en detrimento de la construcción de la democracia participativa». FRANCO CUERVO, A. B. op. cit., 2014, p. 57.

${ }^{28}$ RIVERA ARDILA, R. Y CARDONA SALDARRIAGA, R. op. cit., 2011, p. 232. 


\section{AlFREdo RAmírez NÁRDIZ}

confianza de los mismos en el entramado institucional y en las posibilidades reales que tienen de actuar en la vida pública exigiendo y obteniendo responsabilidades sobre sus gobernantes, etc. Son todos elementos que determinan que la revocatoria de mandato en Colombia, si bien fuera en el primer país suramericano donde se constitucionalizó, tenga en el presente un desarrollo y práctica ciertamente humildes.

\section{El caso venezolano: la revocatoria al Presidente de la República $^{29}$}

Desde la aprobación de la Constitución de 1999, la democracia participativa venezolana es uno de los modelos más variados y novedosos del mundo ${ }^{30}$. También es objeto de no pocos debates y polémicas $^{31}$. Entre los diversos mecanismos participativos que regula, la revocatoria de mandato aparece poderosa al haberse llegado al extremo, en su ejercicio, de someter a la misma al Presidente de la República.

La Constitución de Venezuela de 1999 en su art. 70 define la revocatoria como un medio «de participación y protagonismo del pueblo, en ejercicio de su soberanía, en lo político» e indica -art. 72- que todos los cargos y magistraturas de elección popular son revocables, incluyendo, por tanto, al Presidente de la República. Para iniciar la revocatoria se necesita que haya transcurrido la mitad del periodo por el que fue elegido el funcionario y que un número no inferior al $20 \%$ de los electores inscritos en la correspondiente circunscripción solicite la convocatoria de un referendo para revocar el mandato del funciona-

${ }^{29}$ En este punto se sigue el punto 3.5 titulado «Venezuela: la revocación de mandato» de la obra RAMÍREZ NÁRDIZ, A. Guía práctica de la democracia participativa. Conocer la democracia participativa y aprender a usarla, Dykinson, Madrid, 2012.

30 "Aunque en Venezuela se había experimentado con algunos instrumentos aislados de democracia directa, su uso sistemático en el ámbito nacional se inicia con el ascenso de Chávez al poder y se mantiene a lo largo de sus años en la presidencia (1999-2013)». KORNBLITH, M. «Venezuela: polarización, revocatoria y después» en WELP, Y. Y SERDÜLT, U. (COORDS.) op. cit., 2014, p. 112.

${ }^{31}$ Hay autores que consideran que el uso de la democracia participativa en Venezuela "ha sido intenso; ha carecido del debido desarrollo legal e institucional, lo que se ha traducido en disposiciones acomodaticias condicionadas por las circunstancias; la activación de la democracia directa enfrentó más obstáculos bajo la Constitución de 1999 que en el marco de la Constitución de 1961; y cuando los instrumentos de la democracia directa fueron enarbolados por sectores opositores al gobierno tropezaron con severos impedimentos para su activación.» KORNBLITH, M. Democracia Directa y Revocatoria de Mandato en Venezuela, International IDEA, Buenos Aires, 2007, p. 3. 
rio al que se quiera apartar del cargo. Se tiene por revocado el mandato y se procede a cubrir su falta cuando igual o mayor número de electores que los que eligieron al funcionario voten a favor de la revocatoria, siempre que hayan concurrido al referendo un número de electores igual o superior al 25\% del electorado inscrito. No puede hacerse más de una solicitud de revocatoria durante un único periodo de mandato de un funcionario. El diputado al que se le haya revocado el mandato no puede ocupar cargos de elección popular en el siguiente periodo -art. 198-.

La regulación de la Constitución se complementa por las Normas para Regular los Referendos Revocatorios, de $2007^{32}$ (reformadoras de las de 2003). Estas normas regulan en sus casi 250 artículos el procedimiento concretando aspectos como el rol de las Juntas Electorales, la publicidad y la propaganda, el financiamiento de la campaña, la instalación y constitución de la mesa del referendo, la votación y el escrutinio, la auditoría del sistema de votación, la proclamación de los resultados, etc.

El referendo revocatorio más famoso y relevante, por alcanzar a la máxima magistratura nacional, se desarrolló el 15 de agosto de 2004 y trató sobre la continuidad o no en el cargo del Presidente de la República, Hugo Chávez ${ }^{33}$. El elevado nivel de polarización social que se vivió (y que, aunque se acrecentó con el referendo, no se generó a raíz del mismo, sino que se remontaba en el pasado varios años) $)^{34}$ se pudo observar hasta en la definición dada a la votación que para unos era un referendo revocatorio, mientras que para otros era un referendo ratificatorio. Evidentemente, a nivel político no es lo mismo revocar a un gobernante, que ratificarlo.

${ }^{32}$ REPÚBLICA BOLIVARIANA DE VENEZUELA. PODER ELECTORAL. CONSEJO NACIONAL ELECTORAL. Resolución $n^{\circ}$ 070327-341, por la que se dictan las normas para regular los referendos revocatorios, Caracas, 27 de marzo de 2007, 196 y $148^{\circ}$.

${ }^{33}$ Precedido de otro intento previo de revocatoria organizado en 2003 para el cual se reunieron más de tres millones de firmas en una iniciativa de los opositores a Chávez conocida popularmente como «el firmazo»: «Las solicitudes fueron presentadas ante el CNE el 20 de agosto de 2003. En este caso la mayoría progubernamental del órgano comicial decidió en contra de la iniciativa. Los tres directivos pro-oficialistas alegaron el incumplimiento de «formalidades esenciales» por parte de los promotores de la consulta, como la extemporaneidad de la recolección de firmas y la falta de mención del organismo electoral en el encabezado de las planillas (CNE)». KORNBLITH, M. op. cit., 2014, p. 114.

${ }^{34}$ LISSIDINI, A. «Democracia directa en Venezuela: ¿Participación política controlada?», Documento de Trabajo, n. ${ }^{\circ}$ 32, Escuela de Política y Gobierno, Universidad Nacional de San Martín, Argentina, abril 2008, p. 24. 


\section{ALFREdo RAMÍREZ NÁRDIZ}

La petición de convocatoria de la revocatoria fue promovida y solicitada por la Coordinadora de Acción Democrática (alrededor de la cual se agrupó la oposición al presidente Chávez: agrupaciones empresariales -Fedecámaras-, partidos políticos -AD, Primero Justicia-, organizaciones sociales, etc.). La petición se presentó el 20 de agosto de 2003, pero apenas un mes más tarde la Comisión Nacional Electoral la declaró inadmisible a causa, entre otros factores, de que las firmas necesarias para respaldar la petición se habían recogido antes de que se cumpliera la mitad del mandato del presidente Chávez; además, unos meses más tarde, la Comisión no aceptaría como válidas más de un millón de firmas presentadas por los solicitantes $^{35}$. Ante estas decisiones de la autoridad electoral, desde dentro de las filas de los solicitantes se promovieron actos de desobediencia civil que degeneraron en protestas y actos violentos. Finalmente la Comisión aceptó como válidas las aproximadamente dos millones y medio de firmas necesarias para convocar la revocatoria y el proceso comenzó ${ }^{36}$.

La pregunta fue: «¿Está usted de acuerdo con dejar sin efecto el mandato popular, otorgado mediante elecciones democráticas legítimas al ciudadano Hugo Rafael Chávez Frías, como presidente de la República Bolivariana de Venezuela para el actual periodo presidencial?» La participación fue del 69.92\% (9.815.631 votantes sobre un censo de 14.037.900 electores), siendo el resultado favorable a la continuidad del Presidente Chávez con un 59.09\% (5.800.629 votos) contrario a su revocación frente a un 40.64\% (3.989.008 votos) que se inclinó por solicitar que se le removiera del cargo ${ }^{37}$.

El proceso en su conjunto fue polémico. Organizaciones internacionales como la Organización de Estados Americanos o el Centro Carter lo avalaron y lo consideraron legal, pero simultáneamente criticaron a la Comisión Nacional Electoral por falta de transparencia y le pidieron que mejorara los mecanismos de recolección, verificación

${ }^{35}$ La actitud de la Comisión Nacional Electoral ha sido considerada por algunos como una intromisión excesiva en el proceso, criticándose que impuso condiciones no equitativas y en exceso onerosas a los solicitantes de la revocatoria. Entre otras circunstancias, el periodo de verificación de firmas se extendió hasta los cien días, cuando no debía durar más de treinta, arguyéndose que se impusieron sobre la marcha criterios de invalidación de firmas muy discutidos. KORNBLITH, M. op. cit., Buenos Aires, 2007, pp. 9-10.

${ }^{36}$ LISSIDINI, A. op cit., Universidad Nacional de San Martín, Argentina, abril 2008, pp. 24-27.

${ }^{37}$ REPÚBLICA BOLIVARIANA DE VENEZUELA. CONSEJO NACIONAL ELECTORAL. JUNTA NACIONAL ELECTORAL. GERENCIA GENERAL DE AUTOMATIZACIÓN. www.cne.gov.ve//referendum_presidencial2004/ Consultado, 11 agosto 2014. 
y reparación de firmas, así como que mejorara su colaboración con la oposición al Gobierno y con los observadores internacionales. La oposición, por su parte, denunció que se había producido un fraude masivo y que los resultados estaban adulterados ${ }^{38}$.

La experiencia venezolana puede interpretarse en el sentido de considerar que, si bien la revocatoria de mandato nace con voluntad de ser un instrumento participativo cuyos objetivos son someter a un mayor control y exigir una mayor responsabilidad a los gobernantes, en la práctica puede ser un mecanismo que materialice la confrontación social en sociedades especialmente polarizadas ${ }^{39}$. Una herramienta para discutir no tanto sobre ideas, sino sobre personas, simplificando cualquier mensaje o ideario político a un simple sí o un no sobre la continuidad del líder. Lo cual, lejos de suponer una mejora de la democracia, lo que trae consigo es un empeoramiento de la misma.

Tampoco hay que ignorar los peligros que tiene tanto la revocatoria, como toda la democracia participativa, de ser utilizada como instrumento no de complemento de la democracia representativa, sino como de substitución de la misma, estableciendo una relación directa entre gobernante carismático y pueblo (mantenida y materializada mediante un recurrente recurso a las preguntas a la ciudadanía, como si de un poder constituyente permanentemente activo se tratara), postergando las instituciones políticas (especialmente al parlamento) y dificultando la labor de los partidos de la oposición ${ }^{40}$.

${ }^{38}$ LISSIDINI, A. op. cit., Universidad Nacional de San Martín, Argentina, abril 2008, p. 29.

39 «No obstante, la dinámica sociopolítica subsiguiente llevó a colocar la figura de la revocatoria del mandato en el centro de la confrontación y del debate político, como expresión de la polarización y el antagonismo que caracterizaban las relaciones entre el gobierno y la oposición en aquellas circunstancias, y que siguieron marcando la larga permanencia de Chávez en la presidencia hasta su fallecimiento, el 5 de marzo de 2013». KORNBLITH, M. op. cit., 2014, p. 116.

40 «La inclusión de la democracia directa o participativa en el entramado valorativo e institucional venezolano es compartida por otras naciones y textos constitucionales de América Latina; sin embargo, en la constitución venezolana vigente, la democracia directa se presenta en oposición a la democracia representativa. Esta tensión queda plasmada en el texto, entre otros aspectos, cuando se prescinde de la connotación representativa al referirse a la forma de gobierno (art. 6), se excluye del texto la mención a los partidos políticos denominándolos «asociaciones con fines políticos» y se prohíbe el financiamiento público de sus actividades (art. 67). Además, por la tendencia general a exacerbar el poder ejecutivo en detrimento del principio del equilibrio entre los poderes (...) Existe abundante literatura acerca de las tendencias antiliberales y antidemocráticas del régimen político inaugurado con el ascenso de Chávez al poder y su particular combinación con la participación y las 


\section{LA REVOCATORIA EN ESPAÑA}

\section{Una cuestión de modelo: presidencialismo y parlamentarismo}

Para plantearse una posible introducción de la revocatoria de mandato en el ordenamiento jurídico español la primera cuestión que hay que resolver es si la misma casaría con el modelo político parlamentario español o, por el contrario, si resultaría, de tan extraña, ajena e imposible de insertar en el ordenamiento español, a salvo de que el mismo fuera modificado y alterado en su carácter parlamentario para transformarse en otro de tipo presidencialista.

El sistema político español es parlamentario. Bien lo dice el art. 1.3 CE cuando indica que la forma política del Estado español es la Monarquía parlamentaria. Esta fórmula manifiesta en las dos palabras que la forman la pareja de elementos característicos de la democracia española: por un lado, la Jefatura del Estado reside en la Corona y, por otro lado, la soberanía es representada por un parlamento elegido por los ciudadanos del que, en mayor o menor medida (y siempre teniendo muy en cuenta el rol de los partidos políticos), surgen las demás instituciones del Estado.

El parlamentarismo como modelo es habitual en Europa Occidental, del mismo modo que el presidencialismo es habitual de América. No es casualidad, por tanto, que la revocatoria esté presente en diversos países americanos, desde los EE.UU. hasta Suramérica, que son repúblicas presidencialistas, mientras que sea extraña en Europa ${ }^{41}$, donde el modelo dominante es el parlamentarismo, ya sea la monar-

elecciones. Entre otros, puede consultarse: Coppedge (2003); Kornblith (2009); Corrales y Penfold (2011). Una visión en su momento más favorable respecto de las potencialidades de la democracia participativa en: López Maya (2005)». Ibídem, 2014, p. 120.

${ }^{41}$ Extraña, pero no inexistente. Así, por ejemplo, en el ámbito municipal alemán existen fórmulas similares a la revocatoria en las cuales la iniciativa de cesar al alcalde surge del pleno municipal y debe ser votada y aprobada por los vecinos. Poniendo como ejemplo Hessen indica DIEZ SASTRE que «la iniciación del procedimiento de revocación ha de proponerse en el Pleno por al menos mayoría de dos tercios o por la mitad del número legal de miembros que lo componen. Para poder presentar esta propuesta de resolución es necesario el transcurso de un cierto período de tiempo desde la elección del alcalde. La aprobación de la revocación requiere la mayoría de los votos válidos emitidos por los vecinos, con la condición de que esa mayoría suponga, al menos, el treinta por ciento del número de personas con derecho a voto en el municipio». DIEZ SASTRE, S. "La elección directa del alcalde en Alemania», Anuario del gobierno local, $\mathrm{n}^{\circ}$ 1, 2004, p. 249. 
quía parlamentaria (España, Reino Unido ${ }^{42}$ ), o la república parlamentaria (Alemania, Italia).

En un modelo parlamentario como el español donde es el parlamento, como sede de la representación de la soberanía popular, quien elige al Presidente del Gobierno, debe ser el parlamento el que, en su caso, retire a dicho presidente la confianza en él depositada previamente. No parece lógico que unos ciudadanos, que no le han votado a él, sino a unos representantes que se postulan a la elección en las listas de un partido que se presenta a las elecciones parlamentarias, puedan retirarle una confianza que, realmente, nunca han depositado en él a título individual, sino en dichos representantes agrupados alrededor de las siglas, la ideología, el programa y las promesas del partido político, por más que él dirija dicho partido ${ }^{43}$.

El ciudadano, mediante su voto y en unas elecciones posteriores, podrá retirar la confianza de los representantes parlamentarios que eligió en su momento y, derivado de ello e indirectamente, provocar la caída del Presidente del Gobierno. Pero en un sistema parlamentario no parece coherente que el ciudadano tenga un instrumento para retirarle la confianza al presidente (ya sea nacional, regional o al alcalde), sino que debe ser aquel que eligió al presidente y le dotó de su

${ }^{42} \mathrm{El}$ ámbito local inglés permite encontrar fórmulas alternativas al modelo parlamentario de elección indirecta del Ejecutivo. Así indica GARCÍA: «el sistema que se sigue actualmente en Reino Unido según la Local Goverment Act de 28 de julio de 2000. Según este sistema, si hay dos candidatos, se elige por mayoría simple y el elector tiene un solo voto. En caso de que haya tres o más candidatos, el elector da un voto preferente a uno de los candidatos a Alcalde (first preference vote) y puede otorgar un segundo voto a otro candidato (second preference vote). En este último caso, el sistema de elección es el siguiente: si uno de los candidatos obtiene mayoría absoluta, será elegido Alcalde. Si ninguno de ellos alcanza tal mayoría, se tienen en cuenta únicamente aquellos dos candidatos que hayan recibido el mayor número de first preference votes y de ellos será elegido el que tenga mayor número de votos, contando tanto los votos de primera preferencia como los segundos». GARCÍA, M. J. «La elección directa del alcalde en el régimen local: justificación, alcance y repercusiones», Revista Española de Derecho Constitucional, ${ }^{\circ}$ 91, enero-abril 2011, p. 212.

${ }^{43}$ Sensu contrario, si son los ciudadanos los que eligen al gobernante, si parece coherente que sean ellos los llamados, en su caso a cesarlo. En este sentido y respecto de los alcaldes: «De admitirse algún mecanismo de destitución, es lógico pensar que la revocación de esa confianza debería realizarse de manera similar a como se otorgó, es decir, por el propio electorado, lo que supondría la implantación de un sistema de destitución de Alcaldes mediante revocación popular, figura que no es totalmente desconocida en nuestro Derecho, ya que el Estatuto Municipal de 1924 y la Ley Municipal republicana de 1935 contemplaban la revocación del Alcalde por el electorado en los supuestos en que la elección se hubiera realizado de manera directa». Ibídem, p.230. 


\section{ALFREDo RAMÍREZ NÁRDIZ}

confianza, esto es, el parlamento, el llamado a retirársela, siendo la moción de censura ${ }^{44}$ el instrumento más característico para hacerlo ${ }^{45}$.

La crítica al modelo de control basado en la moción de censura, de la que podría salir la justificación de optar por un modelo de control materializado en la revocatoria, partiría de considerar que, en contra de lo que en teoría debería ser, la moción de censura no es un instrumento de control bastante, particularmente en países como Alemania y España donde la moción es de carácter constructivo (es decir, donde se retira la confianza a un Presidente del Gobierno, pero con el requisito de tener que proponer en la misma moción de censura un candidato a nuevo Presidente del Gobierno), pues más sirve para dotar de estabilidad la posición del Presidente, para censurar al cual no basta con una mayoría parlamentaria que así lo desee, sino que además se requiere que esa mayoría acuerde un sustituto, que para ejercer ningún tipo de control verdaderamente efectivo ${ }^{46}$.

En este sentido, es una crítica habitual que en los sistemas parlamentarios, donde en teoría el parlamento debería ser el centro de la vida política, pero donde en la práctica es crucial el juego de los partidos políticos y el papel del partido mayoritario que sustenta al Gobierno, es el Gobierno y especialmente su Presidente quienes acaban centralizando la acción política, pudiendo ser su posición sólo altera-

${ }^{44}$ «La moción de censura es definida, en el texto constitucional y en los Estatutos que se contempla, como el procedimiento mediante el que el Parlamento puede exigir responsabilidad política al ejecutivo, lo que supone que el Gobierno tiene «la obligación de responder por, y de soportar las consecuencias de, sus actos ante los ciudadanos o sus representantes, de quienes en última instancia depende» (...) El régimen parlamentario tiene como elemento esencial la existencia de la responsabilidad política, mediante la que se manifiesta una relación fiduciaria que vincula el Gobierno al Parlamento y cuya máxima expresión será la capacidad de remover al Ejecutivo. La contrapartida al posible cese del Ejecutivo es la capacidad de disolución del Parlamento por el Gobierno.» SORIANO HERNÁNDEZ, E. «El uso de la moción de censura en las Comunidades Autónomas", Asamblea. Revista parlamentaria de la Asamblea de Madrid, $\mathrm{n}^{\circ}$ 15, diciembre 2006, p. 25, citando a MONTERO GIBERT, J. R. Y GARCIA MORILLO, J. El control parlamentario, Tecnos, 1984, pp. 126-127.

${ }^{45}$ Pero no el único. Junto con la moción de censura, la Constitución prevé diversos mecanismos para que las Cortes controlen al Gobierno tales como la cuestión de confianza (art. 112), las interpelaciones y preguntas (art. 111), o la facultad de las Cámaras y sus Comisiones de reclamar la presencia de los miembros del Gobierno (art. 110).

${ }^{46}$ De manera casi «profética» indicaba ya en 1979 MONTERO GIBERT que «tampoco en España parece probable que la moción de censura constructiva pueda tener una influencia decisiva en la estabilidad gubernamental», para concluir sobre la moción de censura en España que «el carácter superfluo del art. 113 resulta, pues, más que presumible. Y su ineficacia, más que probable». MONTERO GIBERT, J. R. «La moción de censura en la Constitución de 1978. Supuestos constituyentes y consecuencias políticas», Revista de estudios políticos, n 12 , 1979, pp. 35-36 y 40 . 
da por el voto ciudadano en elecciones periódicas, pero no por los teóricos medios de control con los que cuenta el parlamento, los cuales, en la práctica, o bien no tienen repercusiones reales ${ }^{47}$, o bien su compleja realización ${ }^{48}$ los hace ineficaces ${ }^{49}$.

Resulta complejo imaginar cómo sería posible introducir la revocatoria de mandato en el ordenamiento jurídico español, ya fuese para revocar alcaldes y presidentes autonómicos, o incluso para revocar al Presidente del Gobierno, sin antes modificar de tal modo el modelo que, en la práctica, de uno parlamentario se pasara a uno presidencialista (el art. $140 \mathrm{CE}$ permite la elección directa del alcalde por los vecinos ${ }^{50}$. No habría, por tanto, que reformar la Constitución para introducir la revocatoria, pero optar por la elección directa y por ella sí supondría un cambio de modelo del parlamentario al presiden-

47 «Porque es claro que entendido en sentido restringido, como capacidad de remoción del Gobierno por el Parlamento, la eficacia del control parlamentario sería bien escasa en la actual democracia de partidos dada la (innegable y conveniente) fusión mayoría parlamentaria-Gobierno». ARAGÓN REYES, M. «Parlamentarismo y antiparlamentarismo en el primer tercio del siglo XX. La proyección actual de aquella polémica», Revista de estudios políticos, n 93, 1996, p. 65.

${ }^{48}$ Así, en España, que el Congreso le retire su confianza al Presidente del Gobierno mediante una moción de censura requiere siempre y en cualquier caso una mayoría absoluta (art. 113.1 CE), mientras que otorgarle su confianza puede hacerse, en segunda votación, mediante una mayoría simple (art. 99.3 CE). Es decir, es más complicado retirarle la confianza a un Presidente, que otorgársela.

${ }^{49}$ Sobre Alemania, pero también predicable de España: «la posición del canciller es tan fuerte que, tanto sus enemigos como sus partidarios, se quejan del desempeño autoritario de su cargo. Por la estabilidad del gabinete se ha pagado, de hecho, un alto precio: el proceso democrático ha sido, en parte, paralizado; la mayoría parlamentaria se somete sin protesta al gobierno; la opinión pública no tiene en absoluto influencia sobre la mayoría gubernamental (...) y todavía menos influencia en el gobierno, protegido de la posible destitución por la dificultad de encontrar un sucesor. Al evitar el Escila de la inestabilidad gubernamental, el régimen de Bonn ha caído en el Caribdis de un parlamentarismo castrado. En esencia, el régimen es «demoautoritario» (...): bajo esto se debe entender que, si bien el gobierno llega al cargo en forma democrática, el liderazgo político será posteriormente ejercido autoritariamente y sin ninguna limitación ejercida por el parlamento o el electorado (...). No hay medios efectivos para un control político aparte de las elecciones federales que tienen lugar cada cuatro años (...). El actual sistema es difícilmente apropiado para transmitir el funcionamiento parlamentario o de la democracia». LOEWENSTEIN, K. Teoría de la Constitución, Ariel, Barcelona, 1976, pp. 114-115, en MONTERO GIBERT, J. R. op. cit., 1979, pp. 19-20.

${ }^{50}$ La elección directa de alcaldes no sería una novedad imprevista en el ordenamiento español. Es una posibilidad estudiada y relativamente recurrente en las propuestas de los diferentes partidos políticos: «se trata de una cuestión que ha permanecido en estado latente durante años en el panorama jurídico-político español que, ahora, protagoniza en gran parte el debate de la regulación local, poniendo de manifiesto su relevancia en la configuración de las estructuras políticas de poder, y de la organización interna de la Administración en el ámbito municipal». DIEZ SASTRE, S. op. cit., 2004, pp. 233-234. 


\section{ALFREdo RAMÍREZ NÁRDIZ}

cialista), pues no se trataría únicamente de substituir la moción de censura por la revocatoria de mandato, sino de un completo cambio de paradigma ${ }^{51}$.

Por supuesto, podría mantenerse la elección indirecta de los cargos citados y, simultáneamente, dar al ciudadano la posibilidad de revocar a dichos cargos mediante un referendo revocatorio, pero esto generaría la incoherencia de que pudiera retirar la confianza aquel que en ningún momento la dio, así como la cuestión de ante quién debería ser responsable el gobernante: ¿ante aquellos que le eligen? ¿Ante aquellos que le pueden cesar? ¿Ante los dos? Posiblemente, lo más sensato fuera, o bien cambiar el modelo de parlamentario a presidencialista e incluir la revocatoria en el nuevo modelo presidencialista español, o bien dejar el modelo intacto y no incluir la revocatoria. Pero mantener el modelo incluyendo la revocatoria supondría una anomalía jurídica innecesaria, en cuanto el modelo se puede cambiar, y problemática, por las incoherencias que podría generar ${ }^{52}$.

\section{Introducción de la revocatoria en el Derecho español: elección directa del gobernante y revocatoria}

$\mathrm{Si}$, en el caso de que se desee introducir la revocatoria en el ordenamiento español, se considera que la opción más adecuada es transformar el modelo de uno parlamentario a uno presidencialista, la cuestión a resolver es cómo hacerlo.

${ }^{51}$ El paso desde un modelo parlamentario a uno presidencialista no dejaría sin sentido sólo la moción de censura, sino también otros instrumentos de control como la cuestión de confianza. Así, respecto del ámbito local: «En base a argumentos similares basados en la legitimidad democrática directa de los Alcaldes habría que afirmar igualmente la incompatibilidad de este sistema electoral con la cuestión de confianza, al menos tal y como está concebida actualmente, y ello por dos razones: 1) porque la confianza depositada en el Alcalde procede directamente del electorado, y no del pleno, y 2) porque la legitimidad democrática directa exigible en todo caso a los Alcaldes obligaría a la celebración de nuevas elecciones para la designación de un nuevo Alcalde (...) la implantación de este sistema de elección de los Alcaldes comportaría la necesidad de acometer reformas sustanciales en el diseño de los mecanismos de control y destitución de los Alcaldes, lo que sin duda tendría una importante repercusión en la organización local». GARCIA, M. J. op. cit., enero-abril 2011, p. 230.

${ }^{52}$ Parafraseando a ALZAGA, «la combinación de géneros plantea una gravedad distinta en política que en literatura». HERRERO LERA, M. citando el BOC n. ${ }^{\circ} 109$, de 13 de julio de 1978, pp. 4208-4209, en ALZAGA VILLAAMIL, Ó. «Comentarios a las Leyes Políticas. Constitución Española de 1978», tomo VII, Revista de Derecho Privado, Editoriales de Derecho Reunidas, Madrid, 1985, pp. 216-217. 
Parece correcto considerar que, si son los ciudadanos los que, mediante la revocatoria, han de revocar el mandato dado al gobernante, esto es porque previamente han sido ellos quienes han depositado su confianza en dicho gobernante votándolo y eligiéndolo. Es decir, la introducción de la revocatoria en el ordenamiento jurídico español requiere como elemento previo que todo aquel cargo público que pueda ser revocado por los ciudadanos haya sido previamente elegido de forma directa por dichos ciudadanos ${ }^{53}$.

Dado que esto no es así en el presente en España, sino que los alcaldes $^{54}$, presidentes autonómicos o Presidente del Gobierno, son elegidos por representantes que han sido elegidos antes por los ciudadanos, sería necesario, como paso previo a introducir la revocatoria en el ordenamiento español, transformar el actual modelo parlamentario en uno presidencialista y que tanto alcaldes, como presidentes autonómicos, como el Presidente del Gobierno (si se desea que la revocatoria afecte a los gobernantes sea cual sea su ámbito territorial de actuación) sean elegidos directamente por los ciudadanos ${ }^{55}$.

Aunque el objeto de este artículo es la revocatoria y no la elección directa, que se muestra sólo como un elemento previo a la misma,

${ }^{53}$ En este sentido apunta GARCÍA FERNÁNDEZ respecto a la elección directa del alcalde: «hay que señalar con rotundidad que la filosofía política que permite la elección directa del Alcalde se quebraría si se permitiese que un órgano que no lo eligió, el Pleno, pudiera cesarlo: en Estados Unidos y en Francia no existe moción de censura contra el Presidente aun cuando el impeachment pueda utilizarse torticeramente, como ocurrió con el Presidente Clinton. Entendemos por tanto que la elección directa del Alcalde enerva de radice cualquier posibilidad de moción de censura por el Pleno». Es decir, el sujeto que cesa al gobernante puede cesarlo porque previamente lo eligió. GARCÍA FERNÁNDEZ, J. «La elección directa de los alcaldes: contexto político y problemática jurídica», Revista de Derecho Político, UNED, n ${ }^{52}$, 2001, p. 240 .

${ }^{54}$ La regla general por la que en España al alcalde se le elige de forma indirecta por los concejales elegidos previamente por los ciudadanos tiene dos excepciones bien conocidas: los municipios que funcionen en régimen de concejo abierto y los alcaldes pedáneos. Los primeros, tal como dice el art. 179.2 de la LOREG, eligen a su alcalde de forma directa por los electores a través del sistema mayoritario. Los alcaldes pedáneos, por su parte, como apunta el art. 199.2 de la LOREG, son también elegidos directamente por los vecinos de la entidad local correspondiente mediante el sistema mayoritario (siempre a salvo de la regulación autonómica que regule este punto y siempre que esta regulación autonómica respete lo dispuesto en la Ley Reguladora de las Bases del Régimen Local).

${ }^{55}$ Es interesante el caso del cabildo abierto, donde los ciudadanos eligen directamente a su alcalde y donde pueden igualmente deponerlo mediante una moción de censura que, en atención a lo que indica el art. 197.4 de la Ley Orgánica del Régimen Electoral General, más parece una revocatoria de mandato o, en todo caso, un instrumento de democracia participativa, que una verdadera moción de censura (entendida ésta como un instrumento de control parlamentario), tal y como se refiere a ella el artículo. 


\section{ALFREdo RAMÍrEZ NÁRDIZ}

quepa apuntar que una reforma que fuera encaminada a permitir estas elecciones directas debería probablemente tener en cuenta las siguientes disposiciones ${ }^{56}$ :

- Constitución Española, 1978: art. 1.3: forma política del Estado (Monarquía parlamentaria); art. 99: otorgamiento de confianza por el Congreso al candidato a Presidente de Gobierno y nombramiento por el Rey del mismo; art. 101: pérdida de la confianza parlamentaria del Gobierno como causa de cese; art. 108: responsabilidad solidaria del Gobierno ante el Congreso; art. 112-114: cuestión de confianza y moción de censura; art. 140: permite tanto la elección indirecta, como la directa de alcaldes

- Ley 7/1985, de 2 de abril, reguladora de las Bases del Régimen Local (art. 19.2, respecto a la elección del alcalde, la cual queda abierta a que sea efectuada por los concejales o por los vecinos $^{57}$, en los términos que disponga la legislación electoral general), en relación con la Ley 57/2003, de 16 de diciembre, de medidas para la modernización del gobierno local, y las modificaciones introducidas por ésta en la Ley 7/1985.

— Ley Orgánica 5/1985, de 19 de junio, del Régimen Electoral General (en lo relativo a las elecciones municipales, especialmente el Título III, Capítulo IX, particularmente el art. 196, que indica que la elección del alcalde la efectúan los concejales).

${ }^{56}$ Cualquier enumeración legislativa cerrada podría no ser oportuna, en el sentido apuntado por reflexiones de fondo como la que hace GARCÍA respecto de la introducción de la elección directa del gobernante en el ámbito local: «la implantación de un sistema de elección directa en toda su extensión requeriría una profunda modificación del sistema electoral que afectaría incluso al esquema de organización y funcionamiento de las entidades locales». GARCIA, M. J. op. cit., enero-abril 2011, p. 213.

${ }^{57}$ Convertir la elección de los alcaldes en una elección directa por los vecinos ya se ha intentado en el pasado: «A finales de 1998 el Grupo Parlamentario Socialista del Congreso presentó una proposición de ley orgánica que tenía por objeto modificar la elección de los Alcaldes, quienes pasarían a ser elegidos directamente por los electores (BOCG, Congreso de los Diputados, VI legislatura, serie B, núm. 256-1,7 de diciembre de 1998) (...) El Partido Socialista Obrero Español, por su parte, elaboró un documento titulado El reto de la autonomía local, debatido en marzo de 1998 por su Consejo Territorial y por su Comité Federal, en el que se suscitaba la elección directa del Alcalde por todos los electores del municipio por considerar que acrecentaría la identificación de los electores con los Alcaldes al tiempo que permitiría conformar mayorías de gobierno más estables». GARCÍA FERNÁNDEZ, J. op. cit., 2001, pp. 207 у 209. 
— Ley 50/1997, de 27 de noviembre, del Gobierno (art. 2.2.c en lo relativo a la cuestión de confianza; art. 26.2 sobre el control político de los actos y omisiones del Gobierno por las Cortes).

- Estatutos de Autonomía de las diferentes CC.AA. en lo relativo a la elección del Presidente de la CC.AA. y a la pérdida de su confianza en él de la Asamblea de la CC.AA., así como la regulación derivada.

Siendo la elección directa un hecho, y siendo la ciudadanía quien eligiera directamente el gobernante, sería posible que esta misma ciudadanía tuviera la facultad de cesar a quien nombró, por ello, se podría introducir la revocatoria de mandato en el ordenamiento español incorporando la regulación de la misma (y, tal vez, la de alguna institución que siguiera la línea del voto programático colombiano) a las normas citadas.

\section{Posibles consecuencias de la revocatoria}

Cabe la posibilidad de plantear los posibles efectos, tanto deseables como no deseables, que podría causar la introducción y práctica de la revocatoria de mandato en el Derecho español:

a) Efectos positivos ${ }^{58}$ :

1. Aumento del control de los ciudadanos sobre sus gobernantes: derivado de la posibilidad de revocar su mandato en el caso de que se considere que su gestión no ha sido adecuada.

2. Acercamiento de los ciudadanos a la vida pública: al dotárseles de un mecanismo que les permite una mayor participación e implicación en el gobierno de su comunidad, con el consiguiente fortalecimiento de la democracia ${ }^{59}$.

${ }^{58}$ Las enumeraciones de efectos positivos son diversas: «aumenta el interés de los electores en los asuntos políticos, al permitirles la participación directa en decisiones de gran relevancia; obliga a los gobernantes a mantener una relación más cercana con el electorado; le recuerda al gobernante que su labor es evaluada directamente por el ciudadana y por último, faculta al elector a destituir el funcionario cuando haya perdido la confianza en él». RIVERA SÁNCHEZ, J. L. op. cit., 2006, p. 15.

${ }^{59}$ En esta dirección se posiciona SUBIRATS cuando apunta que «la complejidad de las situaciones sociales hoy requieren abordajes colectivos para definir los problemas y para buscar soluciones a los mismos. Lo relevante no es tanto diseñar buenas políticas para resolver los problemas de la gente desde una posición jerárquica de poder, conocimiento y «expertise», sino implicar a la gente en la definición de los puntos problemáticos y en el desarrollo de las alternativas que puedan buscarse, aceptando que el conocimiento es plural y las políticas deben compartirse desde sus momentos iniciales para que sean efectivas.» SUBIRATS I HUMET, J. «Democracia, 


\section{ALFREDo RAMÍREZ NÁRDIZ}

3. Mayor formación política de los ciudadanos: el ciudadano que participa más en la vida pública tiende a interesarse más en ella, adquiriendo conocimientos que de otro modo no habría adquirido y posiblemente ni siquiera le hubieran interesado ${ }^{60}$.

4. Aumento de la identificación del ciudadano con su comunidad: el ciudadano que percibe que junto con sus iguales forma parte de un todo capacitado para actuar y tomar decisiones políticas tiene más posibilidades de no verse como un sujeto aislado en una sociedad desestructurada, sino como un miembro de una comunidad activa con la que se identifica.

5. Disminución de la corrupción y de las prácticas políticas ilícitas: hipotéticamente, los gobernantes verán aumentadas sus motivaciones para no caer en ningún tipo de actividad ilegal si saben que los ciudadanos descontentos disponen en la revocatoria de un instrumento para cesarles sin necesidad de acudir a un proceso judicial (cuya tramitación sea, posiblemente, más larga y compleja).

b) Efectos negativos:

1. Limitación de la libertad del gobernante en su acción de gobierno: las circunstancias pueden cambiar obligando al gobernante a tener que tomar medidas que considere necesarias pero que contraríen su programa político. Si el gobernante se ve obligado a cumplir su programa en cualquier caso, aun y cambiando las circunstancias, y bajo riesgo de revocatoria, su libertad de acción se ve muy perjudicada y la propia acción de gobierno se puede volver ineficaz o, incluso, perjudicial para los gobernados.

2. Riesgo de populismo: el gobernante puede tener la tentación de adecuar su acción de gobierno a aquello que considera que más les

participación y transformación social», Polis: Revista Latinoamericana, $\mathrm{n}^{\circ}$ 12, 2005, http://polis.revues.org/5599 Consultado, 19 de noviembre de 2014.

${ }^{60}$ En esta dirección señala FONT, sobre los núcleos de intervención participativa (instrumento local de la democracia participativa): «Los NIP no actúan sólo como mecanismos para tomar una decisión, sino como instrumentos de educación democrática. Los participantes reconocen abrumaduramente que su interés por los asuntos públicos se ha incrementado y los gobernantes se sienten más comprendidos cuando un conjunto de ciudadanos ha tenido que asumir responsabilidades que no les son propias y «mojarse» sobre qué terreno hay que expropiar si es preciso, sobre dónde hay que buscar los fondos para construir la autovía o sobre qué instalaciones no son imprescindibles en el polideportivo local. En definitiva, a través de los participantes y del efecto multiplicador que éstos puedan realizar al explicar su actividad, el NIP ha contribuido a que exista una mayor educación democrática, en el más amplio sentido de la palabra (participación, diálogo, responsabilidad)». FONT, J. «Los núcleos de intervención participativa (NIP): análisis de tres experiencias», Gestión y análisis de políticas públicas, $\mathrm{n}^{\circ} 5-6,1996, \mathrm{p} .148$. 
gustará a los ciudadanos (o a la parte de ellos de la que depende su reelección) despreciando cualquier otra variable en su proceso de toma de decisiones y con el único fin de mantenerse en el poder ${ }^{61}$.

3. Falta de estabilidad y continuidad en la acción de gobierno: unas circunstancias adversas (por ejemplo, en lo económico) pueden llevar a unos ciudadanos insatisfechos y dotados de la posibilidad de revocar a sus gobernantes a revocarlos una y otra vez interrumpiendo su acción de gobierno, no dejando que esta se desarrolle e impidiendo incluso la solución de dichas circunstancias adversas ${ }^{62}$.

4. La revocatoria puede convertirse en un instrumento pobre para controlar al Poder Ejecutivo: si el partido que lo apoya dispone de mayoría en el Parlamento, el Ejecutivo puede imponer en su regulación unos requisitos de difícil consecución real, tales como tantos por ciento elevados para convocar la revocatoria, para tenerla por válidamente realizada, o para aprobarla. Si se concibe la revocatoria como el instrumento natural de control sobre un Poder Ejecutivo elegido directamente por los ciudadanos, con capacidad de reelección y ajeno al control parlamentario, pero los requisitos para convocarla son exigentes en exceso, en la práctica no habrá revocatorias y el Poder Ejecutivo actuará sin ningún control efectivo sobre su acción de gobierno más allá de las sucesivas convocatorias electorales. Es decir, la revocatoria puede convertirse en un instrumento cosmético o de imagen en manos de un Ejecutivo que busque perpetuarse en el poder evitando cualquier posible control real como lo son los parlamentarios (si a eso se le suma la eliminación de la prohibición de reelección -contrapeso a la elección directa del Ejecutivo- el poder del titular del Ejecutivo podría ya ser desproporcionado respecto a los otros poderes del Estado).

5. La revocatoria puede conllevar, frente al instrumento parlamentario de la moción de censura, un debate superficial y menos desarrollado y sopesado sobre los motivos y razones para, en su caso, cesar al gobernante. La decisión popular, más que en motivos racionales o, como mínimo, de interés u oportunidad política, puede moti-

${ }^{61}$ La revocatoria «se puede convertir en un instrumento amedrentador que impida el adecuado desempeño del cargo, dado que siempre estaría presente la amenaza de someterlo al escrutinio, si no satisface los intereses de determinados grupos». RIVERA SÁNCHEZ, J. L. op. cit., 2006, p. 15.

62 «Sin embargo, si bien la participación política es importante, no se debe soslayar que es necesario observar el impacto que pueda producir en la estabilidad del gobierno cuya autoridad se cuestiona. En otras palabras, la participación importa, pero la gobernabilidad también». TUESTA SOLDEVILLA, F. op. cit., 2014, pp. 7-8. 
varse exclusivamente en las filias o fobias personales del electorado sobre el cargo político concreto a cesar ${ }^{63}$.

6. La revocatoria supone colocar en el centro de la vida política al titular del Poder Ejecutivo. Es decir, fomenta el personalismo en la acción de gobierno, especialmente si el gobernante sometido a la revocatoria la gana y continúa en el cargo. Es posible considerar que la revocatoria, propia de sistemas presidencialistas, es síntoma de personalismo en la vida pública, pero también se puede indicar que implica en sí misma una potenciación del mismo al focalizar la decisión de los ciudadanos no tanto sobre un programa de gobierno, sino, en muchas ocasiones, sobre un gobernante concreto, una persona determinada ${ }^{64}$.

7. Como cualquier instrumento participativo, la revocatoria corre el riesgo de provocar el resultado inverso al deseado, esto es, que los ciudadanos, ante el exceso de participación política de ellos demandada, se abstengan de participar agotados ante un número excesivo de convocatorias. Demasiada participación puede desembocar, a modo de reacción, en una mayor inhibición ciudadana ante la cosa pública $^{65}$.

Por todo lo dicho, se puede concluir que los pros y los contras de la revocatoria son, en gran medida, si no los mismos, sí gran parte de los $\operatorname{pros}^{66}$ y contras ${ }^{67}$ que tiene la democracia participativa como todo.

${ }^{63}$ Como indica SUBIRATS «Hace ya años, un magistrado de la Corte Constitucional italiana, Gustavo ZAGREBELSKY, ponía de relieve la falta de adecuación entre los presupuestos deliberativos de la democracia y la precipitación no exenta de demagogia que rodean los referéndums instantáneos, y para ello utilizaba el ejemplo bíblico de la elección directa y popular que decidió entre Barrabás y Jesucristo». SUBIRATS I HUMET, J. op. cit., 2011, p. 129.

${ }^{64}$ No en vano, es posible considerar que si la revocatoria, aun y existiendo, tiene en Suiza una repercusión bastante baja es porque la vida política helvética huye de todo personalismo. WELP, Y. Y SERDÜLT, U. (COORDS.) op. cit., 2014, p. 6.

${ }^{65}$ El ejemplo suizo parece apuntar en esta dirección, pues en este país existen indicios de que convocar a votar a los ciudadanos en un número elevado de ocasiones puede llevarles no a implicarse más en la vida pública, sino, por el contrario, a inhibirse y votar menos. Así, es posible observar como las tasas de participación en los referendos suizos ha bajado alrededor de veinte puntos porcentuales desde 1945 hasta el presente. RAMÍREZ NÁRDIZ, A. op. cit., 2012. Sobre la idea de que un exceso de posibilidades de participación puede provocar el hastío del votante, vide FONT, N. Democràcia i participación ciutadana, Mediterrània, Barcelona, 1998.

${ }^{66}$ Sobre los pros vide RAMÍREZ NÁRDIZ, A. «La participación como respuesta a la crisis de la representación: el rol de la democracia participativa», Revista de Derecho Político, $\mathrm{n}^{\circ}$ 90, UNED, 2014, pp. 177-210.

${ }^{67}$ Sobre los contras indica SUBIRATS: «si nos referimos más en concreto a los problemas que pueden surgir en la implementación de las propuestas de democracia directa reseñadas, algunos de los que se han señalado como más significativos son la 
Esto es, la revocatoria, como instrumento participativo, tiene similares pros y contras que cualquier otro instrumento participativo. Por un lado puede servir para profundizar y mejorar la democracia. Pero, por el otro, puede ser herramienta del populismo y de un gobierno movido más por las necesidades coyunturales de los ciudadanos y por su deseo de mantenerse en el poder, que por un verdadero plan a largo o medio plazo para la comunidad.

\section{CONCLUSIONES}

A la hora de valorar una hipotética introducción de la revocatoria de mandato en el Derecho español, la cuestión fundamental sería, en definitiva, la siguiente: ¿introducir la revocatoria de mandato en el ordenamiento español sería una mejora o un empeoramiento del modelo político nacional? Tal vez, la respuesta consistiría en indicar que, más que un cambio positivo o negativo sobre el modelo existente, lo que implicaría la revocatoria y las reformas necesarias para introducirla con propiedad en el ordenamiento jurídico español sería un cambio de modelo. Un cambio desde el modelo parlamentario al modelo presidencialista. Un cambio desde el modelo de elección indirecta de gobernantes al de elección directa.

Teniendo en cuenta que la forma política que la Constitución de 1978 instaura merced a su artículo 1.3 es la Monarquía parlamentaria (y que el art. $152 \mathrm{CE}$ opta también por el parlamentarismo para las CC.AA. del $151 \mathrm{CE}$; parlamentarismo por el que igualmente se han inclinado las restantes CC.AA.), parece evidente que la Carta Magna concibe España como un modelo parlamentario, con lo que introducir un instrumento participativo propio del modelo presidencialista supondría quebrar la concepción constitucional e insertar en la forma política prevista por el constituyente una cuña ajena a la misma. Con las discordancias que eso supondría.

La Constitución sí prevé, sin embargo, la posible elección directa del alcalde por los vecinos en su art. 140, por lo que sí sería posible,

falta de continuidad y de estrategia definida en la opinión de la ciudadanía, la falta de información y debate suficiente, sin asunción de responsabilidades sobre los efectos de las decisiones tomadas, el peligro de falta de participación que permita el control del voto en ciertas decisiones por parte de minorías con intereses muy definidos, o el exceso de complejidad en las políticas o decisiones a tomar, o los problemas derivados del propio uso de las TIC, su control, garantías... El punto en el que se alude a la falta de preparación de la ciudadanía para enfrentarse a la complejidad de los temas que hoy nutren los debates legislativos es probablemente el más de fondo». SUBIRATS I HUMET, J. op. cit., 2011, p. 130. 


\section{ALFREDo RAMÍREZ NÁRDIZ}

sin modificación constitucional, la introducción de la revocatoria de mandato en el ámbito local español. Sería relativamente sencillo modificar la regulación actual (la LOREG y la Ley Reguladora de las Bases del Régimen Local) ${ }^{68}$, permitir este tipo de elección directa y, con ello, abrir la puerta a la revocatoria dentro de esa nueva lógica presidencialista ${ }^{69}$. Sin olvidar que, en todo caso, cualquier modificación normativa en esta dirección implicaría la introducción de elementos presidencialistas en un modelo esencialmente parlamentario. En los otros ámbitos territoriales, la introducción de la revocatoria posiblemente requiriese modificaciones no sólo legales, sino también constitucionales, en el sentido de permitir la elección directa del gobernante, haciendo con ello más compleja dicha introducción.

En todo caso, y si se asumiera como un hecho consumado la reforma constitucional y legal necesaria para insertar la revocatoria de mandato en el ordenamiento español, la verdadera cuestión es si la misma supondría una mejora democrática o, por el contrario, una involución de la democracia (o no tendría efecto alguno, ni bueno, ni malo). Sobre esto, y en función de las experiencias internacionales observadas, parece posible al menos plantear que la revocatoria puede implicar un aumento del personalismo en la vida política del país. La pregunta planteada a los ciudadanos en la revocatoria no se hace tanto sobre la ideología o el plan de gobierno del gobernante sometido a la misma, sino sobre el gobernante en sí, sobre la persona. La revocatoria, en este sentido, focaliza la vida democrática sobre un líder político. ¿Hasta qué punto un gobernante ratificado en una revocatoria puede ser en la práctica controlado o limitado en su poder por ninguna institución del Estado una vez ha obtenido una ratificación popular expresamente personalizada en él?

Si se examina desde este punto de vista, la revocatoria produce, ya sea por su propia naturaleza o por una consecuencia derivada del uso viciado de la misma (su uso populista), un estado de cosas en el que

68 «Lo que quiere ponerse de manifiesto es que el sistema de elección del Alcalde no requiere de modificación constitucional, por lo que queda abierto a las distintas opciones que el legislador crea conveniente implantar en un momento determinado». GARCÍA, M. J. op. cit., enero-abril 2011, p. 208.

${ }^{69} \mathrm{La}$ libertad de elección que otorga la Constitución bien podría haberse conducido por la legislación en un sentido distinto a aquel en el que finalmente se condujo: «el artículo 140.1 de ésta dejó deliberadamente abierta la forma de elección de Alcaldes, de tal modo que éstos pueden ser elegidos por los Concejales o por los vecinos. El proyecto de Ley de Elecciones Locales de 1978 que elaboró el Gobierno del Presidente Suárez preveía, por su parte, que sería proclamado Alcalde el cabeza de la candidatura más votada pero finalmente el texto aprobado por las Cortes Generales vino a establecer un procedimiento de elección indirecta a través de los Concejales». GARCÍA FERNÁNDEZ, J. op. cit., 2001, p. 208. 
el Poder Ejecutivo se relaciona directamente con los ciudadanos, toma su poder de ellos, convierte la vida pública en una relación dual entre el líder carismático que interpreta la voluntad del pueblo y el pueblo mismo y debilita cualquier posible control que ningún otro poder público pueda ejercer sobre el gobernante.

Si la democracia es más que la mera elección popular de representantes y gobernantes, si es algo más que la toma de decisiones públicas por la regla de la mayoría, esto es, si la democracia requiere, entre otros muchos elementos, de los controles, de los contrapesos, de la limitación de los poderes públicos por los propios poderes públicos, la revocatoria sí puede tenerse como un instrumento jurídico potencialmente susceptible de debilitar la democracia, aun y no siendo, en principio, ese su objetivo.

No deja de ser esta una crítica muy cercana a la bien conocida postura defendida por SARTORI cuando diferenciaba entre la democracia representativa y la democracia refrendaria y apuntaba los notorios peligros que las fórmulas de la segunda pueden suponer convirtiéndose en herramientas que, en manos de demagogos y buscando alcanzar un hipotético ideal democrático, acaben destruyendo la democracia. Siendo como es la revocatoria un instrumento de participación directa de los ciudadanos en la vida pública, es evidente que es susceptible de compartir los peligros señalados por SARTORI. ${ }^{70}$

Ante la complejidad de la integración de la revocatoria en el ordenamiento español, tanto por lo ajeno que resulta a España este instrumento participativo de control, propio de un modelo presidencialista, como por los posibles efectos perniciosos que pudiera tener sobre la vida democrática nacional (personalismos, populismo, etc.), teniendo en cuenta también los efectos positivos que podría generar (acercamiento de los ciudadanos a la vida pública, aumento del control sobre los gobernantes, etc.), y sin entrar a valorar la preferencia por un modelo presidencialista o por uno parlamentario, es en todo caso posible apuntar que en el presente y en España intentar y, en su caso, conse-

${ }^{70}$ «En suma, la democracia refrendaria centuplica los riesgos de manipulación y embrollos del demos, más allá de cuánto haya logrado el demagogo del que tenemos conocimiento (...) Con la democracia refrendaria se toca el momento de la verdad en el que el ideal de la democracia etimológica sería realizado al pie de la letra y se tocaría también, preveo, el momento en el cual el ideal se vuelve su opuesto y se autodestruye (el éxito inverso en el que cae, sin falta, el perfeccionista) (...) la democracia representativa es a menudo mal gobierno pero de todas formas es democracia. Temo que donde llegaba a haber una presunta superación, la democracia dejaría rápidamente de ser tal». SARTORI, G. ¿Qué es la democracia? Taurus, México, D. F. 2007, pp.120-131. 


\section{ALFREDO RAMÍREZ NÁRDIZ}

guir la introducción de la revocatoria podría resultar tal vez más un problema que una mejora democrática.

Quizás la democracia participativa y sus diferentes instrumentos jurídicos, uno de los cuales es la revocatoria de mandato, puedan ser efectivamente un medio útil para la mejora y profundización de la democracia, pero más que probablemente siempre que se planteen como complemento ${ }^{71}$ a la democracia representativa y no como alternativa que substituya controles de tipo parlamentario (moción de censura) por otros presidencialistas y participativos (revocatoria).

71 «Las dificultades prácticas y los graves inconvenientes teóricos de la democracia directa han originado que ésta no pueda verse como una alternativa a la democracia representativa, sino, todo lo más, como su complemento» ARAGÓN REYES, M. «Democracia y representación. Dimensiones subjetiva y objetiva del derecho de sufragio», Corts: Anuario de Derecho Parlamentario, n 9, 2000, p. 42. 